\title{
La historia clínica de Wolfang Amadeus Mozart
}

\section{Medical record of Wolfgang Amadeus Mozart}

\author{
Orlando Mejía • Manizales (Colombia)
}

"Mozart nunca se quejaba, ni de sí mismo ni de los demás, a menos que estuviera comprometida su dignidad".

Wolfang HiLdesheimer, Mozart (1977).

\section{Resumen}

Las hipótesis en torno a las patologías que tuvo Wolfang Amadeus Mozart (1756-1791) en su vida, la enfermedad final y la causa de su muerte han generado alrededor de 160 diagnósticos diferentes. En este trabajo se analizan las causas más pertinentes desde el punto de vista de la medicina interna y se plantea que es improbable que fuese un enfermo crónico, o un paciente psiquiátrico, o tuviese un síndrome genético, o hubiese sido envenenado. Se concluye que en los dos últimos meses de su existencia presentó una posible hipertensión arterial sistémica severa y luego desarrolló un síndrome nefrótico o nefrótico-nefrítico causado, quizá, por una fiebre tifoidea y aparecieron las complicaciones de una insuficiencia renal aguda en sus últimos días y un accidente cerebrovascular hemorrágico final. (Acta Med Colomb 2013; 38: xx-xx).

Palabras clave: Mozart, clínica, patobiografía, hipertensión, síndrome nefrótico, fiebre tifoidea, insuficiencia renal aguda, accidente cerebrovascular hemorrágico.

\footnotetext{
Abstract

The hypotheses in regard to the pathologies that had Wolfgang Amadeus Mozart (1756-1791) in his life, the final illness and the cause of his death have generated about 160 different diagnoses. This paper analyzes the most relevant causes from the point of view of internal medicine and suggests that it is unlikely that he were a chronically ill patient or a mental patient, or that he had a genetic syndrome or had been poisoned. We conclude that in the last two months of its existence he had a possible severe systemic arterial hypertension and then developed a nephrotic syndrome or nephrotic - nephritic caused perhaps by typhoid fever, and that in his last days the complications of an acute renal failure appeared and had a final hemorrhagic cerebrovascular accident. (Acta Med Colomb 2013; 38: xx-xx).

Keywords: Mozart, clinic, pathobiography, hypertension, nephrotic syndrome, typhoidfever, acute renal failure, hemorrhagic stroke.
}

Dr. Orlando Mejía: Especialista en Medicina Interna, Especialista en Literatura Hispanoamericana, Maestría en Filosofía con Énfasis en Epistemología. Profesor Titular de Medicina Interna y Humanidades Médicas en el Programa de Medicina de la Universidad de Caldas. Manizales (Colombia)

Correspondencia: Dr. Orlando Mejía E-mail: paracelso2001@yahoo.com Recibido: 22/IV/2013 Aceptado: 28/VI/2013

\section{Introducción}

La historia clínica de un individuo no es importante sino para él, con la excepción de cuando esa persona es un genio de la música como Wolfang Amadeus Mozart (1756-1791), el cual, comparado con los promedios de supervivencia de nuestro tiempo, murió muy joven. Ahora bien, sus enfermedades ni le quitan ni le ponen a su genialidad. Pero, incluso, que estando enfermo continuara con su labor creativa intensa y extenuante sí nos revela la voluntad extraordinaria de su personalidad $(1,2)$.

Las fuentes y documentos que he utilizado para este texto son: las cartas de Wolfang Amadeus Mozart, las cartas de su padre Leopoldo Mozart, las cartas de su hermana Nammerl Mozart (3); los registros de los médicos tratantes, los documentos de médicos que conocieron su caso clínico o que les fue mencionado de segunda mano; los testimonios 
escritos de contemporáneos de Mozart y los recuerdos de testigos de sus enfermedades, o de su muerte, y que años después los contaron a sus primeros biógrafos.

También he tenido en cuenta las hipótesis clínicas realizadas por médicos de épocas posteriores a la del músico, el supuesto cráneo de Wolfang Amadeus y su correlación histórica, antropológica y fisiognómica; por último, los estudios genéticos de restos óseos de la familia Mozart y su comparación con los cabellos y el cráneo atribuido a él.

No obstante, las siguientes consideraciones previas son pertinentes:

1. No existió autopsia del cadáver de Mozart. Por tanto, continuamos en el campo de la especulación clínica, iniciada hace más de 250 años, porque sin autopsia no existe certeza total de las aproximaciones racionales a sus posibles patologías sufridas.

2. La medicina clínica del siglo XVIII todavía no había desarrollado los métodos semiológicos habituales en la medicina contemporánea. Por ejemplo, no existía manera de tomar los signos vitales de forma detallada, ni había un análisis claro de los mismos (temperatura, presión arterial, frecuencia cardiaca, frecuencia respiratoria). Esto es importante porque en las descripciones de las enfermedades de Mozart todo es subjetivo y no tenemos ninguna descripción objetiva y medible.

3. Los nombres con que se mencionaban los síntomas y signos de las enfermedades no siempre corresponden a los actuales. Un caso significativo de ello es el diagnóstico de "Reumatismo o fiebre reumática" que, en el siglo XVIII y hasta mediados del siglo XIX, significaba un estado clínico inespecífico de fiebre y dolor o inflamación en las articulaciones. Esto ha llevado a interpretaciones contemporáneas erróneas, pues dicho diagnóstico no corresponde a lo que se entiende, desde 1861, como el cuadro clínico típico. Descrito por los pediatras ingleses Cheadle y Barlow, con carditis, poliartritis, corea, nódulos subcutáneos y eritema marginado y que el patólogo alemán Aschoff correlacionó con antecedentes de infección faríngea previa a comienzos del siglo XX (4).

4. Varias enfermedades no se conocían y por tanto los médicos de la época no podían diagnosticarlas. Recordemos que Mozart murió en 1791 y a finales del siglo XVIII apenas se estaba gestando el movimiento clínico que daría origen a la nosología moderna, en el siglo XIX, a través de la famosa escuela semiológica francesa.

5. Los mitos románticos alrededor de la figura de Mozart generaron y han generado versiones falsas o acomodadas de la realidad. De hecho, el romanticismo se apropió de la figura de Mozart y por ello necesitaba crear una leyenda de misterio en torno a su muerte (5). Descripciones como la de la hermana de Constanza, de que él antes de entrar en coma intentó imitar el sonido de las trompetas del Réquiem y trató de soplar con sus carrillos, son inverosímiles (6); pues lo más seguro es que Mozart presentó una respiración ruidosa denominada de Cheyne Stokes, de aparición frecuente en un enfermo que acababa de sufrir, tal vez, un accidente cerebrovascular o que tenía un trastorno hidroelectrolítico.

6. Existen en la actualidad cerca de 160 diagnósticos clínicos de enfermedades o estados patológicos atribuidos a Mozart. Entre los que se encuentran la hipocondría, las leucemias, los linfomas, el síndrome de malformación congénita múltiple, la deficiencia de vitamina $\mathrm{D}$, la amiloidosis primaria, la amiloidosis secundaria a una enfermedad de Still, la artritis reumatoidea, el síndrome de Reiter, el síndrome de Behcet, el lupus eritematoso sistémico, la poliarteritis nodosa, la sífilis, la malaria, la tuberculosis pulmonar y renal, el sarampión, la leptospirosis, la septicemia estafilocócica, las rickettsiosis, la epilepsia, la epilepsia del lóbulo temporal, la oftalmopatía de Graves, la tirotoxicosis, etcétera $(7,8,9,10)$. No tendré en cuenta a todos estos, sino aquellos que se basan en las hipótesis más plausibles desde el punto de vista de la medicina interna y que tienen una evidencia histórica, epidemiológica y demográfica en la Europa del siglo XVIII.

Los dilemas médicos en torno a Mozart que voy a tratar de interpretar en este trabajo son:

1. ¿Fue un enfermo crónico o tuvo enfermedades agudas?

2. ¿Cuál fue la posible causa de su enfermedad final y de su muerte?

3. ¿Fue un enfermo psiquiátrico?

4. ¿Fue acaso envenenado?

5. ¿Tuvo un síndrome genético?

6. ¿Es, en realidad, el cráneo del Museo de Salzburgo el del músico?

\section{Cronología de sus síntomas y signos}

Sintetizando los datos de las diversas fuentes usadas se puede establecer la siguiente cronología de sus síntomas y signos:

El 14 de octubre de 1762, ya tenía seis años de edad, presentó "catarro" en la ciudad de Linz. El 21 de octubre de ese mismo año, a su llegada a Viena, tuvo fiebre y le aparecieron nódulos en el cuerpo. Su padre Leopoldo escribió que esos "nódulos" eran "rojos y del tamaño de un Kreutzer, en tobillos, codos y caderas. Duraron más de una semana" (3). El médico dermatólogo Rothman interpretó estas lesiones como un posible eritema nodoso (11).

El 19 de noviembre de 1762, en Viena, tuvo indisposición consistente en tos, debilidad y febrícula. A pesar de eso viajó a Salzburgo, unos días después, porque estaba programado para un concierto de violín y manifestó un cuadro clínico de fiebre y poliartritis que lo redujo a la cama por una semana. Este fue el primer episodio conocido de la inflamación de sus articulaciones, pero se desconoce a cuáles de ellas comprometió. Volvió a su ciudad natal y pasó las navidades asintomático. Durante el año de 1763 gozó, al parecer, de buena salud. En febrero de 1764 reanudó sus giras artísticas y estando en la ciudad de París tuvo fiebre, dolor de garganta 
y sensación de ahogo. Se recuperó plenamente y estuvo sin enfermarse hasta el 20 de mayo de ese mismo año cuando sufrió una indisposición inespecífica que, según cuenta su papá, lo tuvo en la cama durante diez días.

El resto del año no volvió a enfermarse y durante 1765 vivió saludable hasta el mes de agosto, cuando refirió un severo escalofrío y dolor de garganta en la ciudad francesa de Lilie, compatible con una amigdalitis que también enfermó a su padre Leopoldo. Su recuperación fue completa, pero el 15 de noviembre de ese mismo año, mientras se encontraba en la ciudad holandesa de La Haya, le apareció una fiebre súbita, alta y persistente que lo obligó a guardar cama. Se ha planteado que pudo ser un "tifo intestinal" o fiebre tifoidea, patología endémica en esa época en Holanda y el resto de Europa, pues su hermana Nammerl había tenido "tifo intestinal" el 12 de septiembre anterior y cuando su hermano cayó en cama apenas se estaba aliviando ella (2). La recuperación plena de Mozart sólo se logró en la primavera de 1766.

El 12 de noviembre de ese mismo año y cuatro días después de llegar a la ciudad de Munich, presenta el segundo episodio de fiebre y poliartritis, el cual le duró ocho días. Regresa a Salzburgo y allí permanece hasta mayo del año siguiente, con una actividad que le permitió estrenar la primera parte de un Singspiel sacro K 35 y la comedia en latín para música K 38 conocida como Apolo y Jacinto. A mitad de septiembre viaja con su familia a Viena y se encuentran con una epidemia de viruela en dicha ciudad.

Huyen a Brno el 23 de octubre y luego viajan a Olmutz. El 26 de octubre de 1767 Mozart se enferma de viruela y deben permanecer allí hasta el 24 de diciembre, porque aunque el músico se curó a comienzos de noviembre, su hermana adquirió también la temible enfermedad hacia el día 10 de noviembre. Las secuelas de las cicatrices de la viruela en el rostro de Wolfang fueron moderadas, pero lo obligaron el resto de su vida a incrementar la cantidad de polvos faciales en sus conciertos públicos.

Los años de 1768 y 1769 transcurrieron con un Mozart sano y activo, componiendo música sacra, la ópera cómica La falsa ingenua $K 46 a \mathrm{y}$, por primera vez, fue designado como "tercer maestro" en dos conciertos ante la corte de Salzburgo el 14 de noviembre de 1769. Luego hace su primer viaje a Italia y en Milán compuso su primer cuarteto para cuerdas en sol mayor K 73f, a mediados de marzo de 1770. Viajó después a la mítica ciudad de Florencia y allí tuvo escalofríos y fiebre durante casi cuatro días. Se recupera sin problemas y continúa su correría por toda Italia, donde la fama y el reconocimiento iban en ascenso, hasta ser incluso atendido con su padre Leopoldo por el santo papa Clemente XIV en audiencia privada el 8 de julio de ese año.

En Bolonia conoce al afamado compositor el padre Martini, quien le da clases diarias y el 26 de diciembre estrena en Milán la ópera Mitrídates, rey del Ponto. El año de 1771 fue uno de los más activos y la mayor parte del tiempo dio recitales y conciertos en las ciudades italianas.
En enero de 1772, en su ciudad natal Salzburgo, le apareció una ictericia que ha sido interpretada como una posible hepatitis viral A, aunque el médico Peter J. Davies no descarta una fiebre amarilla (12). Al parecer Mozart no manifestó complicaciones compatibles con una cronicidad de la hepatitis u otros signos de hepatopatía persistente, pues su recuperación fue completa y durante los siguientes seis años estuvo saludable y creó, de manera constante, obras de valor como, entre otras, la Sinfonía en Sol menor K. 173dB, el concierto para piano K. 175 en Re mayor, la ópera cómica La falsa jardinera K. 196, la Missa brevis en Do mayor K. 196b y el Concierto para piano en Mi Bemol mayor K. 271.

Sólo hasta el 20 de febrero de 1778, estando en Mannheim, manifestó una indisposición transitoria compatible con una infección respiratoria alta que se curó en menos de cinco días. De nuevo, tuvo un periodo de completa salud durante los tres años siguientes hasta el 10 de mayo de 1781, cuando le apareció, en Viena, fiebre súbita y malestar general, que lo llevó a recluirse por ocho días.

El resto de ese año y durante el año de 1782 interpretó y compuso a un ritmo frenético, donde aparecen obras como la ópera Idomeneo rey de Creta, Kyrie en Re menor K. 368 a, Serenata para vientos en Si Bemol mayor K. 370 a, Serenata para vientos en Mi Bemol mayor K. 375 y el 16 de julio de 1782, en el Burgtheater de Viena, se hace la primera ejecución del exitoso Singspiel El rapto del serrallo K. 384.

El 4 de agosto de ese año se casa con Constanza Weber. Se muda a Viena con su mujer y allí nace su primer hijo, Raimundo Leopoldo, en abril de 1783. A finales de mayo Wolfang presenta un escalofrío severo y dolor de garganta intenso compatible con una amigdalitis aguda. El 19 de agosto fallece su primogénito de una infección intestinal de la infancia. Aunque mostró evidencias de gran tristeza, su trabajo creativo nunca disminuyó.

A comienzos del año de 1784 Mozart inició el catálogo de sus obras y su primer trabajo comunicado fue el concierto para piano en Mi Bemol mayor K. 449. Además daba clases de piano en su casa y ejecutaba conciertos privados en casas de nobles. En agosto de ese año le apareció, de manera aguda e intensa, fiebre, artralgias, cólico abdominal y vomito frecuente. Fue el primer episodio de dos más que se repitieron en abril de 1787 y en abril de 1790 y que para algunos biógrafos médicos evidencia un síndrome de Henoch-Schoenlein, que se discutirá más adelante.

De 1785 a 1790 la vida de Mozart fue muy difícil, pues se juntaron sus permanentes crisis de solvencia económica con la muerte de su amado padre Leopoldo en mayo de 1887, la de su segunda hija Teresa en junio de 1788, la enfermedad de su esposa Constanza y, sobre todo, una tensa relación de pareja que se deterioraba de manera acelerada. Sin embargo, la lucidez intelectual del músico seguía siendo extraordinaria y en este lustro escribió las partituras de obras tan representativas como los cuartetos en La mayor K. 464 y Do mayor K. 465, los conciertos para piano en Re menor K. 466, en Do mayor K. 467 y en Mi Bemol mayor K. 482, 
la ópera Las bodas de Fígaro, la Sinfonía en Re mayor K. 504, la ópera Don Giovanni, las sinfonías en Mi Bemol mayor K. 543, en Sol menor K. 550, en Do mayor K. 551 y los exquisitos Cuartetos en Si bemol mayor K. 589 y en Fa mayor K. 590.

En el año de 1791 la salud de Mozart se deterioró en los últimos dos meses. De hecho, en el primer semestre intentó seguir su ritmo de conciertos públicos (aunque el último lo dio el 4 de marzo), e inició la escritura de su inmortal opera La flauta mágica en mayo. Además, compuso el motete Ave rerum corpus K. 618, escribió una ópera por encargo titulada La clemencia de Tito, terminó La flauta mágica K. 620 y él mismo la dirigió en su primera presentación en el Deutsche Opera de Viena el 30 de septiembre.

Sin embargo, a mediados del mes de octubre, según los comentarios de su esposa Constanza a Nissen, comenzaron a aparecer síntomas de labilidad emocional, depresión, cambios abruptos de la personalidad, alucinaciones de tendencia paranoide (este síntoma se infiere a partir del dudoso testimonio dado por Constanza, varios años después, donde dijo que Mozart le relató "que lo estaban envenenando") (6, 13) y a finales de ese mes tuvo también cefaleas frecuentes e intensas, visión borrosa, palidez y anemia, y una pérdida significativa y progresiva de peso.

Los síntomas y signos de las dolencias de Mozart se hicieron más intensos, pero su voluntad de guerrero o místico lo hizo aceptar el último encargo oficial de su existencia: El Concierto para clarinete en La mayor K. 622 para Antonio Stadler y dirigió su Pequeña cantata masónica K. 623 el 18 de noviembre en el nuevo templo de la logia masónica de Viena. Luego volvió a su casa y nunca más volvería a salir vivo de ella.

El 20 de noviembre se inició su enfermedad final: fiebre, artralgias generalizadas, poliartritis de manos y pies durante la primera semana. Luego, a comienzos de la segunda semana, aparecieron edema generalizado (posible anasarca), vómitos intensos y frecuentes, diarrea, exantema generalizado, cefaleas (Mozart refiere en una carta que "se tenía que vendar la cabeza" por el dolor) (3). En los últimos tres días presentó episodios de obnubilación y somnolencia, aunque conservó su lucidez intelectual. Dos horas antes de la muerte entró en un coma profundo. Murió el 5 de diciembre a la una de la madrugada. Tenía sólo 35 años de edad.

\section{Registro de la muerte}

En los últimos días de su enfermedad fue tratado por dos médicos. El uno el doctor Mattias von Sallaba (17541797) y fue éste el que redactó el diagnóstico del registro oficial de su muerte: "Hitziges Frieselfieber" (Fiebre miliar aguda) (14,6). ¿Que significaba esto para la época? Era un diagnóstico inespecífico, que aludía a la condición clínica de fiebre acompañada de un exantema cutáneo.

El otro, que lo trató más tiempo, fue el Dr. Thomas Franz Closset (1754-1813). El dejó constancia de que Mozart murió de "un depósito alla testa" (en la cabeza) (1,
7). Aunque este dictamen ha sido interpretado, por varios médicos y biógrafos contemporáneos, como sinónimo de meningitis, o encefalitis, o tumor cerebral; e incluso, de sífilis meningoencefalítica, lo que él quiso decir, a la luz de la patogenia de la época, fue que el músico falleció de una "fiebre inflamatoria y reumática", que se suponía era una entidad que producía depósitos de material reumático en las articulaciones y en el cerebro. Pero este diagnóstico no tiene nada que ver con lo que conocemos en la medicina moderna como "fiebre reumática".

Por tanto, los dos diagnósticos clínicos oficiales son inespecíficos. Es decir, ambos médicos tratantes no supieron, en realidad, de qué murió Mozart. A continuación se analizarán, de manera sucinta, algunas cuantas hipótesis que poseen plausibilidad científica.

\section{¿Fiebre reumática?}

Autores médicos como Bar (1966) (7), Katner (1969) (7), Neumayr (1994) (15), Baroni (1997) (16), la internista Faith Fitzgerald (2001), profesora en la escuela de medicina de la Universidad de California (17), y Miranda (2008) (18), entre otros, han planteado que la fiebre reumática fue adquirida por él desde la infancia y su evolución crónica lo llevó a la muerte. Teniendo en cuenta los criterios diagnósticos de Jones, Mozart pudo tener un criterio mayor (dos episodios comprobados de poliartritis) y dos criterios menores: fiebre y poliartralgias. El cuadro de "eritema nodoso" de sus seis años de edad podría ser también plausible con otro criterio mayor: el eritema marginado.

Sin embargo, tiene en contra la ausencia de signos de corea, de historia de nódulos subcutáneos y, en especial, de carditis. Pues él no presentó palpitaciones, ni disnea crónica, de ningún grado, a lo largo de su vida. Cuando murió presentó anasarca sin dificultad respiratoria evidente, lo que descarta una insuficiencia cardiaca debida a las secuelas de una posible carditis. Aunque hasta el $60 \%$ de los pacientes con fiebre reumática aguda evolucionan, según Carapetis (19), a una cardiopatía reumática con valvulopatía mitral, es evidente que no se explicaría la muerte de Mozart por una fiebre reumática crónica que no hubiese comprometido después de tantos años las válvulas cardiacas. Como refiere el aforismo médico: "la fiebre reumática lame las articulaciones y muerde al corazón".

\section{¿Síndrome de Henoch-Schöenlein?}

El médico inglés Peter J. Davis $(20,21)$ planteó esta otra posibilidad clínica y el famoso biógrafo Robbins Landon (22), en su bello libro titulado 1791: El último año de Mozart (1988), acoge este mismo diagnóstico. El síndrome de Henoch-Schöenlein consiste en una vasculitis primaria de pequeños vasos, generalizada, que afecta la piel, las articulaciones, el intestino y los riñones. Produce una púrpura palpable (en especial en las nalgas y en miembros inferiores), se acompaña de poliartritis y afecta los riñones generando una glomerulonefritis. Para Davis, el primer episodio que 
presentó Mozart del síndrome fue en 1784, con recaídas en 1787 y 1790 . En ellos se manifestó la tétrada del exantema, de la poliartritis, del dolor abdominal, y de una posible glomerulonefrítis posestreptoccócica. El Henoch-Schöenlein le habría generado una insuficiencia renal crónica y en el último año de su vida una nueva infección estreptocócica le pudo reagudizar su falla renal y le causó la muerte.

En contra estarían lo siguientes hechos: la rareza de la enfermedad, que sólo $10 \%$ de los pacientes hacen un compromiso renal severo y persistente, la imposibilidad de corroborar los antecedentes de una infección epidémica por estreptococo beta y la baja incidencia de mortalidad que tiene esta patología. Además, como refiere Karkahusen (1991) (23) no está clara la relación entre la infección estreptocócica y el desarrollo del síndrome de Henoch-Schöenlein.

Sin embargo, el argumento más sólido para dudar de esta hipótesis es histórico y epidemiológico: en el siglo XVIII la mayor parte de las defunciones eran por enfermedades infecciosas, comunes y agudas, y no existen descripciones semiológicas en la medicina europea compatibles con el Henoch-Schöenlein. De hecho, como mencionan Cantillo Guzmán e Iglesias Gamarra (24), las primeras referencias clínicas de esta (y otras vasculitis) se le deben al dermatólogo Robert Willen (1757-1812), realizadas entre los años de 1798 y 1808.

\section{¿Insuficiencia renal crónica?}

Los médicos Karhausen (1987) (25), Guillery (1992) (26) y Hatzinger (2006) (27) han defendido este diagnóstico fisiopatológico. Esta posibilidad es menos específica, pero, en mi concepto, amerita un análisis detallado. Lo primero para recordar es que Mozart tenía agenesia del lóbulo auricular de la oreja izquierda, hélix vertical y antihélix prominente (28, 29). En la mayoría de los dibujos y óleos que se le realizaron se observa cubierto, en esa zona, por una peluca. Pero en el dibujo que contiene la famosa biografía de Nissen aparece el defecto referido. Además, existe una pintura de Hans Halsen, realizada en 1798 a los dos hijos de Mozart, donde se le observa el mismo defecto del papá a su hijo Wolfang Amadeus Junior (30).

Lo interesante de este hallazgo es que existe una relación establecida entre los defectos congénitos del pabellón auricular y la presencia de diversas anomalías renales congénitas. Ahora bien, esta asociación es del 20\% al 30\% y los defectos renales encontrados son, entre otros, la agenesia renal unilateral, el doble uréter, la enfermedad poliquística renal. Estas alteraciones predisponen a un mayor número de episodios infecciosos de pielonefritis y ello conduce a la posibilidad de desarrollar una insuficiencia renal crónica (IRC).

La hipótesis de Karhausen y Guillary es que Mozart tuvo varios episodios de infección urinaria en su infancia y adolescencia y, por lo menos, dos cuadros clínicos compatibles con pielonefritis. Esto reflejaría la existencia de una anomalía renal congénita predisponente, que lo condujo a su falla renal crónica y a una uropatía obstructiva al final de su vida. De hecho, el clínico francés Barraud, en el temprano año de 1905, ya había planteado esta misma posibilidad médica (31).

Es indudable que durante la mayor parte de los activos y creadores años de la juventud de Mozart no existieron síntomas ni signos compatibles con una IRC, ni tampoco son claros los episodios infecciosos, pues al revisar la fuente bibliográfica primaria, que son las cartas de la familia Mozart, no se relatan síntomas de uretritis, o de lumbalgia, ni de orinas hematúricas o malolientes (3). Lo único sería adjudicar los diversos episodios febriles que tuvo a una causa infecciosa renal, pero este criterio es muy débil desde el punto de vista semiológico.

De otro lado, aunque Mozart tuvo una estatura de aproximadamente 1.61 metros (32), sus retratos no evidencian signos de retardo pondoestatural severo, que se esperaría en niños con infecciones urinarias a repetición y anomalías renales congénitas asociadas. En un reciente trabajo Yamashita (2011) (33) y sus colaboradores han identificado que los defectos del pabellón auricular de Mozart estaban constituidos por un aspecto bulboso de la aurícula, una concha con una concavidad sobresaliente y la presencia de una hendidura con estrechamiento del orificio del conducto auditivo externo. Estos hallazgos son muy inusuales y ellos plantean que es un síndrome raro, donde sólo han encontrado cuatro pacientes, y éstos no tenían la asociación con anomalías renales congénitas.

Sin embargo, los autores de esta teoría han argumentado que la IRC sí explicaría la mayor parte de sus dolencias durante los años de 1790 y 1791, incluyendo el evento final donde murió. Los vómitos, las náuseas, las cefaleas, la debilidad son signos de uremia, el "sabor metálico" que le refirió Mozart a su esposa, unos días atrás, creyendo que lo estaban envenenando también lo da la IRC. Incluso, las flebotomías que le hicieron los dos médicos tratantes explicarían la reagudización de su falla renal crónica.

De hecho, los trastornos mentales que, al parecer, tuvo él, desde el embotamiento y las depresiones, hasta el insomnio y las tendencias de paranoia están presentes en los pacientes renales crónicos. No obstante, está en contra la gran actividad creativa de Mozart durante su último año de vida. Pues en esos meses escribió sus óperas La flauta mágica y $L a$ clemencia de Tito, la pequeña cantata masónica K 622 y su famosísimo Réquiem que dejó incompleto. Es indudable que Mozart fue un genio inigualable, pero es casi imposible que un ser humano con somnolencia, obnubilación y debilidad extrema, dadas por la falla renal crónica, trabajase como él, escribiendo todos los días de manera compulsiva, entre las seis de la mañana y las dos de la madrugada, durante los últimos meses de su existencia.

Además, al revisar las cartas de Mozart de su vida adulta se evidencia un hombre de gran energía, al tanto de la vida política, con una intensa actividad social, bohemio, y con una agenda artística extenuante, que no son compatibles con un enfermo crónico por un daño renal, que en general tienen síntomas inespecíficos de debilidad y malestar varios años 
antes de que aparezca el cuadro clínico típico de la uremia. Incluso, Jenkins (1995) (34) ha recordado que en agosto de 1790 Mozart le escribe a su esposa Constanza y le dice que tuvo cefalea y dolor dental. Pero luego, en más de veinte cartas que le manda a ella, no vuelve a manifestarle ningún otro síntoma o molestia. De hecho, en una carta del 3 de julio de 1791 Mozart le refiere que: "En cuanto a mi salud me siento muy bien" $(3,30)$.

Solo seis semanas antes de morir (en la última semana de octubre de 1791) él le cuenta a su esposa y amigos que tiene "catarro" y se siente algo indispuesto. Por último, sin argumentos clínicos o biográficos sólidos, otros autores, como Wheater (1990) (35), ha propuesto que Wolfang Amadeus murió por una IRC causada por una tuberculosis renal sin compromiso pulmonar.

\section{¿Endocarditis bacteriana subaguda o endocarditis bacteriana aguda?}

Autores como Treves (1991) (36), Fitzgerald (17) y Cheng (2010) han propuesto que Mozart tuvo una endocarditis bacteriana subaguda. Este último trató de explicar el evento final a partir de una carta que el músico escribió, en la primavera de 1790, a su amigo Puchberg donde le pide dinero prestado y le menciona que le duelen las articulaciones y tiene un intenso dolor de muelas (37). Cheng especula que si Wolfang ya tenía una carditis reumática y le extrajeron una muela, pudo desarrollar una endocarditis bacteriana subaguda que, incluso, explicaría también el cuadro clínico neurológico de sus días finales, debido a un probable embolismo séptico que le ocasionó un absceso del lóbulo frontal.

Sin embargo, en contra tiene un tiempo muy largo de evolución para ser una endocarditis bacteriana subaguda $\mathrm{y}$, en especial, que no tuvo disnea; por lo cual, como ya se refirió, la existencia de una valvulopatía de origen reumático no tiene sustentación. Sartin (2010) (38) y Jong-Koo Lee (2010) (39) han postulado la posibilidad de una endocarditis bacteriana aguda, aceptando como una indiscutible realidad previa que él tenía una carditis reumática. Lee ha dicho que las flebotomías hechas por sus médicos tratantes fueron el foco infeccioso de entrada para la endocarditis.

\section{¿Triquinosis?}

Jan Hirschmann (2001) piensa que el evento final de Mozart pudo corresponder a una triquinosis causada por la ingesta de carne de cerdo contaminada y mal cocida. Su hipótesis nació de un dato epidemiológico clave que encontró en una carta que él le mandó a su esposa Constanza, el 7 de octubre de 1791, donde le dice: “¿Qué comí?, chuletas de cerdo, deliciosas. Las comí a tu salud" (40). Esto sucedió cuarenta y cuatro días antes del inicio de su enfermedad y el periodo de incubación de la triquinosis alcanza hasta los cincuenta días. Además, según Hirschmann, al aplicarle el principio de la navaja de Occam al diagnóstico clínico, esta única patología explicaría casi todos los síntomas y signos de la enfermedad final que tuvo el músico.
Aunque la primera descripción de la triquinosis se le debe a James Paget, en el año de 1835, el autor refiere que explicaría la fiebre, la inmovilidad casi total de sus extremidades (que lo hicieron parecer paralizado), el exantema, las convulsiones (no están documentadas), la gran inflamación de sus manos, brazos y piernas, la diarrea, el vómito, el dolor abdominal, el posible accidente cerebrovascular y el coma de las últimas horas de Mozart.

Sin embargo, existen varios elementos en contra de esta hipótesis. Ehrlich (2002) (41) ha demostrado que la palabra alemana schweineschnitzel, en el contexto de la Viena del siglo XVIII, podía significar "chuleta de cerdo" o "chuleta de ternera". Pero, incluso, si Mozart comió carne de cerdo es improbable que estuviera infectada, por la larva de Trichinella spiralis, porque la alimentación de los porcinos en ese tiempo se basaba en granos y no en residuos cárnicos.

De otro lado, Mozart no presentó dos signos típicos de la triquinosis. El edema facial y periorbitario (presente de un $70 \%$ al $90 \%$ de los pacientes con la triquinosis) y no hay testimonios de que tuviese mialgias. De hecho, como ha referido Dupony-Camet (2002) (42), las mialgias son insoportables, comprometen los maseteros, los músculos del cuello, la lengua, y esto hace que los pacientes hablen con gran dificultad. Mozart se expresó sin alteraciones hasta entrar en coma. Además, existe una relación entre la ausencia o levedad de las mialgias y el buen pronóstico de la patología. Si, en realidad, a él lo mató la triquinosis debió tener mialgias graves como síntoma preponderante y ello no existió. En la época de su muerte tampoco se había identificado esta enfermedad, que casi siempre ha sido rara como causa de muerte.

\section{¿Fue un enfermo crónico o tuvo enfermedades agudas?}

Después de comprobar, con los múltiples testimonios de sus contemporáneos y de sus biógrafos, que Wolfang Amadeus Mozart tuvo una ajetreada actividad física y creativa durante casi toda su vida, incluyendo buena parte de los años 1790 y 1791, mi concepto es que él no fue un enfermo crónico. Además, los episodios de enfermedad, descritos en su infancia y adolescencia, eran típicos y naturales en una época donde no existían las vacunas, ni diagnósticos y tratamientos acertados para las enfermedades infecciosas.

El índice de mortalidad infantil, en el siglo XVIII, estaba entre 49 y $63 \%$ y que Mozart hubiese sobrevivido descarta en él problemas inmunológicos asociados con enfermedades crónicas. De hecho, la expectativa de vida de los habitantes de las grandes ciudades europeas era de 32 años y casi siempre morían por patologías infecciosas (34). Es decir, él tuvo las infecciones agudas de su época y su muerte no puede considerarse prematura de acuerdo con las tasas demográficas de su tiempo.

La iconografía numerosa (once retratos) hecha a Wolfang Amadeus durante su reconocida existencia, lo muestran con un aspecto rozagante, de buen peso y color de piel 
saludable, sin ninguna evidencia de estigmas clínicos de patologías crónicas. Sólo en el retrato realizado por Johann Georg Edlinger (1741-1819), a finales de 1790, se aprecia, por primera vez, un Mozart con una ligera palidez y un leve edema palpebral bilateral. Esta sería la única evidencia de que tuvo una enfermedad crónica compatible con una patología renal.

Sin embargo, las investigaciones históricas de Jenkins (30) demuestran que Mozart no fue retratado en Münich, en el año de 1790, por Edlinger. De hecho, este retrato, encontrado en el año 2005, en el depósito de una galería de Berlín, parece que fue reproducido de una obra previa hecha por Joseph Lange, donde no se evidencian signos de enfermedad. Lo anterior invalida su calidad de documento gráfico de su verdadero estado de salud, pues el retrato es una versión subjetiva del pintor.

\section{Un concepto clínico personal sobre su enfermedad final y su muerte}

A finales de octubre de 1791 él presentó cefalea, visión borrosa, irritabilidad y cambios del humor. ¿Qué entidad explica estos síntomas? Una hipertensión arterial sistémica descompensada o maligna (esencial o secundaria a una glomerulopatía aguda en evolución) que pudo desencadenarse, o agravarse, porque sus médicos le realizaron flebotomías durante los últimos tres años y le extrajeron al rededor de dos litros de sangre que lo llevó a un estado anémico. La razón de este procedimiento (preventivo o terapéutico) se basaba en la teoría humoral que provenía de la medicina griega hipocrática y que todavía estaba vigente en el siglo XVIII europeo.

El 18 de noviembre asistió a la sesión de la logia masónica y es posible que adquiriera allí alguna enfermedad infecciosa (¿epidémica?), pues ya se encontraba inmunosuprimido por la posible ferropenia de la anemia y por el reciente compromiso renal. El 20 de noviembre cayó en la cama y nunca volvió a levantarse. Ese día comenzó su cuadro agudo de fiebre, artralgias, poliartritis de manos y pies, edema generalizado (anasarca), vomito, diarrea, exantema y coma profundo dos horas antes de morir.

Quiero resaltar el cuadro de una posible anasarca sin evidencia de asfixia. Sophie Haibel, su cuñada, le contó al biógrafo Nissen lo siguiente: "Cuanto Mozart cayó enfermo, entre las dos le hicimos una chaqueta de dormir que se podía poner de frente, porque al estar tan hinchado no podía darse vuelta él mismo" (6). En un memorando sin fecha, su hijo Carl Thomas Mozart dijo: "Es especialmente significativo el hecho que unos días antes de morir, se le hinchó tanto el cuerpo que era incapaz de hacer el más mínimo movimiento" (6).

Es decir, la documentada anasarca sin disnea es un cuadro clínico sugestivo de un síndrome nefrótico. Sus síntomas neurológicos y de hipertensión sistémica descompensada o maligna, que terminaron en un probable accidente cerebrovascular hemorrágico, implican un componente nefrítico agregado, aunque también la hipercoagulabilidad del síndrome nefrótico explicaría el posible ACV final.

Entonces, el evento que lo condujo a su defunción fue, quizá, un síndrome nefrótico o un síndrome nefróticonefrítico agravado por una insuficiencia renal aguda debida a una necrosis tubular aguda por hipovolemia (la fiebre, la diarrea, el vomito, las flebotomías).

Ahora bien, siendo el cuadro nefrótico la explicación más plausible de la anasarca, tan evidente para los testigos, ¿seria posible plantear una etiología específica? Quizá pudo estar asociado a un cuadro infeccioso más reciente, adquirido en la sede de la Logia, como una glomerulonefritis posestreptocócica, o una fiebre escarlatina, o una fiebre tifoidea.

Zegers (2009) y sus colaboradores hicieron una pesquisa epidemiológica en la Viena de 1791, entre los meses de noviembre, diciembre y enero de 1792 , y encontraron que las tres principales causas de muerte en ese periodo fueron la tuberculosis, la caquexia y la desnutrición, y el edema. Luego de corroborar la existencia de varios episodios de edema, en hombres jóvenes, en el hospital militar, ellos proponen que Mozart murió por una glomerulonefritis posestreptocócica que se manifestó con un síndrome nefrítico. Los autores también mencionan a la fiebre escarlatina como una causa menos probable (43).

Sin embargo, en mi concepto, es dudoso que alguien que tuvo varios episodios en la infancia compatibles con amigdalitis estreptocócica desarrollara en la adultez este cuadro autoinmune. Además, el componente nefrótico que explica el edema masivo que él presentó no es usual en la glomerulonefritis posestreptocócica.

Ahora bien, me parece más plausible que el síndrome nefrótico o nefrótico-nefrítico fuese ocasionado por la fiebre tifoidea. Pues, aunque no se ha documentado que en la ciudad de Viena se haya presentado una grave epidemia de fiebre tifoidea o tifo durante la época de su enfermedad final, también es cierto que ellas eran endémicas (34), y frecuentes las epidemias de estas enfermedades en Europa durante el siglo XVIII y sólo hasta después de 1871 se diferenciaron las dos entidades (44).

Además, la fiebre tifoidea, fuera del síndrome nefríticonefrótico, también sería la causa de sus otros síntomas: la fiebre (del 75 al 100\%), la cefalea (del 50 al 90\%), la diarrea (del 37 al 57\%), los vómitos (del 23 al 54\%), el dolor abdominal (del 19 al 39\%) y las manifestaciones neurológicas (del 5 al 12\%) (45, 46).

De hecho, varios autores del pasado, como Bursy (1816), Neukomm (1821), Fichte (1849), Gehring (1883), entre otros, pensaron en tifo (7). Incluso, Lindemann (1996) ha planteado que la expresión "Hitziges Frieselfieber" también significaba "Febris Nervosa" o "tifo abdominal" (7).

En síntesis, el cuadro clínico compatible con la mayoría de los síntomas y signos que tuvo Wolfang Amadeus Mozart, me permiten sustentar la hipótesis de que él falleció de una probable fiebre tifoidea (asociada a un síndrome nefróticonefrítico o nefrótico predominante) y complicada con una 
insuficiencia renal aguda y un accidente cerebrovascular en las últimas horas de su vida.

\section{¿Fue Mozart un enfermo psiquiátrico?}

Distintos autores han planteado que Wolfang Amadeus tuvo trastornos mentales que se pueden identificar y equiparar a las clasificaciones nosológicas contemporáneas. Los principales han sido: depresión mayor (Reischman, 1981 (47), Davies, 1989 (48)), enfermedad bipolar (manía y depresión) (Davis, 1987 (49)). Al intentar diagnosticar sus rasgos de personalidad con la clasificación DSM-IV se ha mencionado el desorden de personalidad dependiente.

Sin embargo, el estudio más convincente es el de Huguelet y Perroud (2005) (50) que consideran que sus estados depresivos deben ser entendidos como depresiones reactivas a situaciones de sufrimiento objetivo: la muerte de su padre y su madre, el fallecimiento de cuatro hijos en la infancia. Además, él vivió de forma casi permanente con problemas económicos, con inestabilidad laboral, sometido a la humillación de tener que solicitar la ayuda de personas que nunca reconocieron su genialidad musical. Es decir, para estos autores Mozart no tuvo una patología mental definida y grave, y quizá podría identificarse un leve espectro bipolar de depresión, inestabilidad emocional y breves episodios hipomaniacos.

De otro lado, el gran escritor francés Stendhal (Henry Beyle), en su breve biografía titulada Vida de Mozart (1815), inició los comentarios de los aparentes tics motores y los gestos del músico, cuando mencionó que: "Su fisonomía no tenía otra cosa de impresionante que su extrema movilidad. La expresión de su semblante cambiaba a cada momento, pero no indicaba otro cosa que la pena o el placer que experimentaba en ese determinado momento. Se observaba en él una manía que generalmente es signo de estupidez: su cuerpo estaba en movimiento perpetuo; agitaba constantemente las manos y golpeaba el suelo con el pie" (51).

Simkin (1992) (52) planteó que pudo tener un síndrome de Guilles de Tourette, porque, también, guiñaba los ojos, subía los hombros, era muy hiperactivo y decía groserías en reuniones de la alta sociedad vienesa. Incluso, este autor revisó 371 cartas que Mozart escribió e identificó palabras soeces o inconvenientes, en 39 de ellas, como "culo, pipí, caca".

Davies (1993) (53) Karhausen (1993) (54), Heyworth (1993) (55), Aterman (1994) (56), Ashoori y Jankovic (2008) (57) y Monaco (2009) (58), entre otros, han refutado la hipótesis de Simkin. De una parte han mostrado que los movimientos curiosos de él no eran tics motores repetitivos e involuntarios, sino ocasionales expresiones hechas para molestar o llamar la atención. Tampoco se ha documentado que tuviera tics fónicos (carraspeo, chasquido de lengua, gruñidos) que son tan habituales en el Guilles de Tourette (59). En relación con la probable coprolalia (palabras malsonantes) y las cartas, Karhausen y Aterman han demostrado que el lenguaje de Mozart correspondía al lenguaje habitual de la clase media de la Viena de su tiempo.
De igual manera, no hay evidencias concluyentes de ecolalia ni ecopraxia. El mismo Karhausen señaló, también, que la expresión "manía" que escribió Stendhal fue una traducción inadecuada que hizo él de la necrológica escrita por Schlichtegroll en 1793. Pero, además, su comportamiento inconveniente era una manera personal de burlarse de los valores y poses de la aristocracia, que despreciaba en el fondo.

Al investigar de manera detallada su biografía $y$, en especial, sus cartas es indudable que él no fue un enfermo psiquiátrico y sus fuertes reacciones emocionales tuvieron una evidente génesis en sus problemas reales y concretos (los duelos, un cierto sentimiento de amargura por la falta de reconocimiento institucional a su genio). Además, fue un niño sin infancia, sometido a un trabajo extenuante y a responsabilidades abrumadoras por parte de su padre Leopoldo. Por el contrario, varias de sus reacciones reflejan, más bien, una personalidad avasalladora y resistente a las circunstancias conflictivas de su vida.

\section{¿Fue envenenado?}

La excelente película Amadeus (1984), del director Miloš Forman y con guión de Peter Shaffer, actualizó en nuestra época el mito de que el compositor Antonio Salieri (17501825) envenenó a Mozart por envidia ante su inigualable talento musical. Ahora bien, el origen de esta versión surgió, al parecer, del mismo Salieri. En el año de 1823 él se encontraba recluido en un asilo con el diagnóstico de "Insania". Este término equivaldría hoy a una "demencia". Entonces, fue un Salieri enajenado el que se autoincriminó de haber envenenado a Mozart. Los rumores se esparcieron por la ciudad de Viena y aparecieron diferentes testimonios que daban fe del asesinato del genio.

Este chisme se fue transformando en verdad histórica y literaria. El escritor ruso Alexander Pushkin (1799-1837) publicó su brevísimo drama Mozart y Salieri (1830), donde imagina que Salieri envenena a Mozart, en la taberna del León de Oro, introduciendo veneno en su copa de vino mientras Mozart le dice que: "Creo que la genialidad es incompatible con el crimen" (60). Luego, el músico RimnskiKorsakov compuso una ópera, en 1897, basada en el drama de Pushkin.

Vincent y Mary Novello, amigos de la viuda Constanza Mozart, citaron en su diario, escrito en 1828, que ella les había dicho que: "Seis meses antes de su muerte, él estaba poseído con la idea de que estaba siendo envenenado con Aqua Toffana y que calcularon que se moriría al acabar su propio Réquiem" (13). Aunque llama la atención que divulgaran esta supuesta confesión sólo después de la muerte de Salieri, no es imposible que Mozart, en realidad, le hubiera manifestado este temor a su esposa, pues él fue contratado para escribir el Réquiem por un personaje desconocido y, en efecto, Mozart escribió en varias cartas que este misterio lo tenía nervioso y con miedo.

Sólo varios años después se supo que el Conde Franz von Walsegg, músico aficionado, había encargado a Mozart el 
Réquiem en secreto, porque pensaba estrenarlo en honor a su esposa, fallecida en febrero de 1791, atribuyéndose su autoría $(61,62,63)$.

Desde el punto de vista clínico es improbable que, en efecto, él hubiese recibido el Aqua Toffana. Esta poción estaba formada por plomo, arsénico y cimbalaria. Su sintomatología consistía en sabor metálico en la boca (que sí tuvo Mozart como ya se mencionó) y en la presencia de una neuropatía periférica y un deterioro mental progresivo, que no son compatibles con la evolución de la patología de Wolgang Amadeus.

La posibilidad de un envenenamiento por otros metales pesados, como el antimonio (que según Ian James (64), clínico del Hospital Real de Londres, lo pudo ingerir él mismo por orden del doctor Closset para tratar la melancolía, la fiebre y la fatiga) y el mercurio (que pudo usar para tratarse una supuesta y dudosa sífilis (65)), si bien podrían explicar la cefalea e incluso, el síndrome nefrótico, es común que tengan una neuropatía periférica que se expresa con una marcha atáxica, que jamás apareció en Mozart. En el caso de la intoxicación por mercurio también aparecen el lenguaje escandido y la sordera, que hubiera impedido su trabajo musical.

En el testamento del Dr. Guldener von Lobes (17631827), amigo de los médicos Sallaba y Closset, y a petición de un amigo de Salieri, de nombre Carpini, él fue enfático en señalar que no se encontró evidencia de envenenamiento en el cadáver de Mozart (6). Es importante resaltar que los médicos de esa época conocían bien los signos del envenenamiento por metales pesados, porque era una práctica criminal habitual en la Europa del siglo XVIII.

A finales del siglo XIX Otto Jahn fue el primero en mencionar que, quizá, los masones lo habían envenenado (32). Lo que sucedió luego es que en el siglo XX la hipótesis del envenenamiento de Mozart tuvo una orientación ideológica. La neuróloga Mathilde Ludendorff, en el año de 1936, planteó la denominada "explicación nazi": los masones y los judíos habían envenenado al compositor porque él era un ario puro y así se justificaba el amor que Hitler y su cúpula militar decían tener sobre su obra.

En síntesis, desde el punto de vista histórico y médico, se puede sustentar que Wolfgang Amadeus no fue envenenado por el Aqua Toffana ni otros metales pesados (la ausencia de marcha atáxica y tremores son significativos), ni por otras sustancias venenosas que estuviesen disponibles en la Viena de finales del siglo XVIII.

\section{¿Tuvo un síndrome genético?}

En los últimos años algunos autores no médicos y novelistas (66) han propuesto que Mozart pudo tener un síndrome de Williams-Beuren, el cual se produce por un defecto genético en el cromosoma 7q11.23 (67), y genera un cuadro que se caracteriza por alteraciones fenotípicas (estatura corta, contractura de las articulaciones, rostro característico con puente nasal bajo, anomalías renales, estenosis aórtica y pulmonar, tórax excavado, esmalte dental defectuoso, entre otros), rasgos de personalidad que incluyen déficit de atención y una tendencia extrema a ser amigables y simpáticos.

También tienen retardo mental (de leve a moderado) y una capacidad excepcional para la interpretación de instrumentos musicales y una memoria musical extraordinaria, que se debe a que ellos poseen hiperacusia, hipersensibilidad auditiva y la capacidad de percibir de manera exacta los tonos auditivos (el denominado en inglés "perfect pitch") que se conoce como "oído absoluto" (68).

Ahora bien, Mozart no manifestó un fenotipo compatible con este síndrome. Pero lo que lo descarta, de manera segura, es que su capacidad intelectual, demostrada en sus cartas y sin tener en cuenta su talento musical, pertenecía a un hombre inteligente y perspicaz, que tenía un conocimiento profundo de la vida cultural de su tiempo. Además, los pacientes con el Williams-Beuren pueden llegar a ser tan asombrosos como la cantante de ópera Gloria Lenhoff (que sabe de memoria más de mil canciones en veinticinco idiomas diferentes), pero ninguno de ellos ha logrado componer música original.

\section{¿Es, en realidad, el cráneo del Museo de Salzburgo el del músico?}

El año de la muerte de Mozart el emperador José II prohibió los entierros dentro de las iglesias por el mal olor. La clase alta y la aristocracia podían pagarse mausoleos familiares, pero la clase media y el pueblo eran enterrados en fosas comunes. Esta es la razón principal de que Wolfang Amadeus fuera enterrado en una sepultura común con otros cinco cuerpos más. A este procedimiento se le denominaba "el ataúd del ahorro" (61).

Al parecer su cráneo fue recuperado por un sepulturero, en el año de 1801, aunque su familia nunca supo donde quedó enterrado porque ellos no fueron al funeral. En el año de 1842 el grabador Jakob Hyrtl afirmó que lo tenía. En 1868 lo regaló a su hermano Joseph Hyrtl, quien era profesor de anatomía. La primera descripción del cráneo se debió a Ludvig August Frank. En el año de 1902 fue adquirido por la Fundación Mozarteum de Salzburgo y de manera oficial se aceptó que era el cráneo de Mozart.

En el año de 1989 se realizó una reconstrucción forense del cráneo y esta reveló concordancia con los retratos conocidos del músico (69). Puech (1989) (70) estableció un dimorfismo craneofacial y un cierre temprano de la sutura metópica. El mismo autor hizo hallazgos compatibles con un hematoma subdural crónico al encontrar una calcificación extradural en la región temporoparietal izquierda (71).

En una hipótesis más polémica Drake (1993) (72) encontró cambios compatibles con un hematoma subdural crónico, secundario a una fractura temporal izquierda, que explicaría la cefalea y los trastornos mentales de los últimos meses y reavivó la hipótesis de que Mozart había sido, quizá, agredido buscando matarlo. Vlcek y colaboradores (2006) van más allá y especulan que el hematoma explicaría la cefalea, 
los cambios de comportamiento y una posible epilepsia del lóbulo temporal (73).

Sin embargo, en un documental de la televisión austriaca titulado Mozart: The Search for Evidence (2006), Whalter Parson y su equipo del Instituto de Medicina Forense de Innsbruck analizaron los restos óseos, provenientes del cementerio San Sebastian de Viena, atribuidos a la sobrina de Mozart (llamada Jeanette) y de su abuela materna, Euphrosina Perlt. Luego hicieron pruebas comparativas de ADN mitocondrial entre los esqueletos, dos dientes del cráneo del museo y unos mechones que se creían pertenecían al músico, pero no se produjo ninguna correlación genética entre los restos óseos, los dientes y el cabello (74).

Aunque de manera oficial no se afirmó sino que "Los muertos se han llevado de nuevo el secreto a la tumba", la interpretación de la prueba descarta, casi por completo, que el cráneo sea el de Mozart o el de alguno de sus familiares cercanos. Pues existe una mayor evidencia histórica de que, por lo menos, uno de los esqueletos analizados sí sea de la familia de Mozart.

\section{Conclusión}

Ninguna teoría diagnóstica puede ser definitiva y conclusiva en la historia clínica de Wolfang Amadeus Mozart. Sin embargo, los documentos biográficos y autobiográficos existentes nos permiten descartar, desde el punto de vista de la interpretación clínica, varias patologías específicas y condiciones como la de que fue un enfermo crónico, o un paciente psiquiátrico, o que tuvo un síndrome genético. De igual manera, es muy improbable que él hubiese sido envenenado al final de su vida. La hipótesis que se ha planteado en este trabajo de un síndrome nefrótico o nefrótico-nefrítico causado, quizá, por una fiebre tifoidea y las complicaciones de una insuficiencia renal aguda en sus últimos días y un accidente cerebrovascular hemorrágico final, tiene una plausibilidad médica a la luz de los elementos clínicos y epidemiológicos que hemos podido conocer, pero tampoco puede ser comprobada.

\section{Declaración de fuentes de financiación y posibles conflictos de interés}

Declaro que en la preparación y realización de este trabajo no he tenido ninguna financiación de parte de empresas farmacéuticas, ni instituciones académicas, ni he recibido estímulos de becas u otros alicientes económicos. De igual manera, declaro que no tengo ningún conflicto de interés con los resultados conceptuales del artículo.

\section{Referencias}

1. Hildesheimer W. Mozart. Bignami A, traductor. Barcelona: Ediciones Destino; 2005. 445 p.

2. Elias N. Mozart, Portrait of a Genius. Cambridge: Polity Press; 1993. 160 p.

3. Mozart W. The letters of Mozart and his family. 3rd edn. Anderson E, Oldman C. B, traductores al inglés. 3 volumes. London: Macmillan; 1985.

4. Massell BF. Rheumatic Fever and Streptococcal Infection: Unraveling the Mysteries of a Dread Disease. Boston: Francis A. Countway Library of Medicine; 1997. $394 \mathrm{p}$

5. Stafford W. The Mozart myths: A critical Reassessment. Stendford: Stanford University Press. 1991

6. Deutsch OE. Mozart, a documentary biography. Blom E, Branscombe P, Noble J, traductores al inglés. London: Adam and Charles Black, 1965. 680 p.
7. Karhausen LR. The bleeding of Mozart, A medical glance on his life, illnesses and and personality. USA: Xlibris Corporation; 2011. 788 p.

8. Rappoport AE. Mozart's primary disease and cause of death: a multiple congienital malformation syndrome based on a genetic, clinical and pathological study. Abstracts XVI Int Congr Acad Pathol 1986; G.476.

9. Grant WB, Pilz S. Vitamin D deficiency contributed to Mozart's death. Med Probl Perform Art 2011; 26(2): 117.

10. Zegers RH, Saeed P, Wiersinga WM. The large eyes of Wolfgang Amadeus Mozart. (On the occasion of the 250th Mozart anniversary year). Int Ophthalmol 2005; 26(6): 201-6.

11. Rothman S. Erythema nodosum in the eighteenth century: the case of the child Mozart. Arch Derm Syph Chic 1945; 52: 33-4.

12. Davies P J. Mozart's illnesses and death. J R Soc Med 1983; 76: 776-85.

13. Medici N, Hughes R, eds. A Mozart pilgrimage. The travel diaries of Vincent and Mary Novello in the year 1829, 3rd edn. London: Euilenberg; 1975.

14. Melograni P. Wolfang Amadeus Mozart, A biography. Cochrane L, traductora. Chicago: The University Chicago Press; 2007. 300 p.

15. Neumayr A. Music and Medicine: Haydn Mozart Beethoven Schubert: Notes on Their Lives, Works, and Medical Histories, Illinois: Medi-Ed Press. 1994. 450 p.

16. Baroni CD. The pathobiography and death Wolfang Amadeus Mozart: from legend to reality. Human Pathol 1997; 28(5): 519-21.

17. Fitzgerald FT, Zaslaw N, Mackowiak PA. Noble heart. Am J Med 2001; 110: 633-40.

18. Miranda M. ¿Qué causó la muerte temprana de Mozart? Rev Med Clin Condes 2008; 19(3): 294-297.

19. Carpetis J. Fiebre reumática. En: Harrison, Principios de Medicina Interna, 18 Ed, Vol 2. México: McGraw Hill. 2012. p. 2752-2757.

20. Davies PJ. Mozart illnesses and death - I The illnesses, 1756-90. Musical Times 1984; 125: 437-42.

21. Davies PJ. Mozart illnesses and death - II The last year and the fatal illness. Musical Times 1984; 125: 554-61

22. Robbins Landon HC. 1791: Mozart's Last Year. New York: Schirmer Books, 1988. 240 p.

23. Karkahusen LR. Contra Davies: Mozart's terminal illness. J R Soc Med 1991; 84: 734-736.

24. Cantillo Turbay JJ, Iglesias Gamarra A. Historia de la púrpura de HenochSchönlein. Acta Med Colomb 2007; 32: 97-100.

25. Karhausen LR. Mozart ear and Mozart's death. BMJ 1987: 294: 511-12.

26. Guillery EN. Did Mozart die of kidney disease? A review from the bicentennial of his death. Editorial Review. J Am Soc Nephrol 1992; 2: 1671-1676.

27. Hatzinger M, Häcker A, Langbein S, Bross S, Honeck P, Alken P. Wolfgang Amadeus Mozart. A urological pathography. Urologe A 2006; 45(4): 489-92.

28. Davies PJ. Mozart's left ear, nephropathy and death. Med J Aust 1987; 147: 581-5.

29. Paton A, Pahor AL, Graham GR. Looking for Mozart ears. Br Med J (Clin Res Ed) 1986; 293: 1622-1624

30. Jenkins JS. Mozart--portrait and myth. J R Soc Med 2006; 99: 288-291.

31. Barraud J. Aquelle maladie a succombé Mozart?. La Chronique Médicale 1905; 12: 737-744.

32. Jahn O. Life of Mozart. Townsend P, traductor al inglés. 3 volumes. London: Novel lo, Ever \& Co. 1882. (formato digital).

33. Yamashita K, Yotsuyanagi T, Saito T, Isogai N, Mori H, Itani Y. Mozart ear: diagnosis, treatment, and literature review. Ann Plast Surg 2011; 67(5): 547-50.

34. Jenkins JS. Mozart and medicine in the eighteenth century. J R Soc Med 1995; 88: $408-413$.

35. Wheater M. Mozart's last illness-a medical diagnosis. JRSM 1990; 83: 586-589.

36. Treves R. Mozart's death. Annals of the Rheumatic Diseases 1991; 50: 963-964.

37. Cheng TO. Mozart's rheumatic heart disease and probable infective endocarditis. Int J Cardiol 2010; 141: 121.

38. Sartin JS. Contagious Rhythm: Infectious Diseases of 20th Century Musicians. Clinical Medicine \& Research 2010; 8: 106-113.

39. Lee JKS. Infective Endocarditis and Phlebotomies May Have Killed Mozart. Korean Circ J. 2010; 40: 611-613.

40. Hirschmann JV. What killed Mozart?. Arch Intern Med 2001; 161: 1381-9.

41. Ehrlich GE. The death of Mozart. J Rheumatol 2002; 29: 643.

42. Dupouy-Camet J. Trichinellosis Is Unlikely to Be Responsible for Mozart's Death. Arch Intern Med. 2002; 162: 946.

43. Zegers R, Weigl A, Steptoe A. The Death of Wolfgang Amadeus Mozart: An Epidemiologic Perspective. Ann Intern Med 2009; 151(4): 274-278.

44. Magner LN. Infectious diseases and the microbial world. Connecticut: Praeger. 2009. $225 \mathrm{p}$ 
45. Jurado Jiménez R, Arenas Muñoz C, Doblas Delgado A, Rivero A, TorreCisneros J. Fiebre tifoidea y otras infecciones por salmonellas. Medicine 2010; 10(52): 3497-3501.

46. Thielman NM, Crump JA, Guerrant RL. Enteric fever and other causes of abdominal symptoms with fever. En: Mandell, Douglas, Bennett, Principles and practice of infectious diseases, seventh edition, vol 1. Usa: Churchill Livingston Elsevier. 2010. p 1399-1412.

47. Reichsman F. Presidential address 1981. Life experiences and creativity of great composers: a psychosomaticist's view. Psychosom Med 1981; 43: 291-293.

48. Davies PJ. Mozart in person: His character and health. New York: Greenwood. 1989. $272 \mathrm{p}$.

49. Davies PJ. Mozart's manic depressive tendencies. Musical Times 1987; 128: 123-6, 191-6.

50. Huguelet P, Perroud P. Wolfgang Amadeus Mozart's psychopathology in light of the current conceptualization of psychiatric disorders. Psychiatry: Interpersonal \& Biological Processes 2005; 68 (2): 130-139.

51. Stendhal. Vida de Mozart. En: Obras Completas, Tomo I, Berges C, traductora. Madrid: Aguilar. 1955. p 90-112.

52. Simkin B. Mozart's scatological disorder. BMJ 1992; 305: 1563-7.

53. Davies PJ. Mozart's scatological disorder. Letter to editor. BMJ 1993; 306: 521-522.

54. Karhausen LR. Mozart's scatological disorder. Letter to editor. BMJ 1993; 306: 522 .

55. Heyworth MF. Mozart's scatological disorder. Letter to editor. BMJ 1993; 306: 522 .

56. Aterman K. Did Mozart have Tourette's syndrome? Some comments on Mozart's language. Perspect Biol Med 1994; 37(2): 247-58.

57. Ashoori A, Jankovic J. Mozart's movements and behaviour: a case of Tourette's syndrome? J Neurol Neurosurg Psychiatry 2007; 78: 1171-1175.

58. Monaco F, Servo S, Cavanna AE. Famous people with Gilles de la Tourette syndrome?. Journal of Psychosomatic Research 2009; 67: 485-490.

59. Kurlan R. Tourette's Syndrome. Clinical practice. N Engl J Med 2010; 363: 2332-8.
60. Pushkin A. Mozart y Salieri. Loaeza G, Molina M, Vela S, traductores al español. Revista de la Universidad de México 2006; 24: 13-15.

61. Braunbehrens V. Mozart in Vienna 1781-1791, Bell T, traductor al inglés. London: Andre Deutsch, 1990. 481 p.

62. Braunbehrens V. Maligned Master: The Real Story of Antonio Salieri. Kanes EV, traductora al inglés. New York: Fromm International Publishing Corporation. 1992. $276 \mathrm{p}$.

63. Cormican, B. Mozart's Death Mozart's Requiem. An investigation. Belfast: Amadeus Press. 1991. 361 p.

64. Epstein RH. Mozart killed by poison, doctor says. En: The daily Gazette, october 21, 1991, p A6.

65. Fluker JL. Mozart, his health and death. Practitioner 1972; 209: 841-845.

66. Moure G. El síndrome de Mozart. Madrid: Ediciones SM. 2003. 176 p. (novela).

67. Schubert C. The genomic basis of the Williams - Beuren syndrome. Cell Mol Life Sci 2009; 66: 1178 - 1197.

68. Wengenroth M, Blatow M, Bendszus M, Schneid P. Leftward Lateralization of Auditory Cortex Underlies Holistic Sound Perception in Williams Syndrome. PLoS ONE 2010; 5 (8): e12326 (Internet). (Citado el 5 de abril de 2013). Disponible en: www.Plosone. org.

69. Puech PF, Puech B, Tichy G. Identification of the cranium of W.A. Mozart. Forensic Sci Int 1989; 41(1-2): 101-110.

70. Puech B, Puech PF, Tichy G, Dhellemmes P, Cianfarani F. Craniofacial dysmorphism in Mozart's skull. J Forensic Sci 1989; 34(2): 487-90.

71. Puech B, Puech PF, Dhellemmes P, Pellerin P, Lepoutre F, Tichy G. Did Mozart have a chronic extradural haematoma? Injury 1989; 20(6): 327-30.

72. Drake ME Jr. Mozart's chronic subdural hematoma. Neurology 1993; 43(11): 2400-3.

73. Vlcek E, Druga R, Smahel Z, Bigoni L, Velemínská J. The skull of Wolfgang Amadeus Mozart predicates of his death. Acta Chir Plast 2006; 48(4): 133-40.

74. García Carrillo A, Pérez Lozano L. ¿Dónde está el cráneo de Mozart? Pasaje a la ciencia. revista de divulgación científica del IES Antonio de Mendoza 2006; número 9, junio (edición digital) (Internet) (citado el 12 de enero de 2013). Disponible en: www.pasajedelaciencia.es. 